Article

\title{
Development of High Sensitivity Humidity Sensor Based on Gray $\mathrm{TiO}_{2} / \mathrm{SrTiO}_{3}$ Composite
}

\author{
Min Zhang ${ }^{1}$, Shunhang Wei ${ }^{2}$, Wei Ren ${ }^{3, *}$ and Rong $\mathrm{Wu}^{1, *}$ \\ 1 The School of Physics Science and Technology, Xinjiang University, Urumqi 830046, China; \\ minzhang0816@163.com \\ 2 Shanghai Key Lab of Chemical Assessment and Sustainability, School of Chemical Science and Engineering, \\ Tongji University, 1239 Siping Road, Shanghai 200092, China; shun_hang@126.com \\ 3 Xinjiang Key Laboratory of Electronic Information Materials and Devices, Xinjiang Technical Institute of \\ Physics \& Chemistry, CAS, Urumqi 830011, China \\ * Correspondence: renw@ms.xjb.ac.cn (W.R.); wurongxju@sina.com (R.W.); \\ Tel.: +86-991-383-5096 (W.R.); Fax: +86-991-858-2405 (R.W.)
}

Academic Editors: Jesús M. Corres and Francisco J. Arregui

Received: 3 May 2017; Accepted: 2 June 2017; Published: 7 June 2017

\begin{abstract}
A gray $\mathrm{TiO}_{2} / \mathrm{SrTiO}_{3}$ composite nanocrystalline sensor with narrow band-gap was successfully prepared through a facile wet chemical method. The precursor was calcined in $\mathrm{N}_{2}$ flow under atmospheric pressure and thereafter, a humidity sensor based on the composite was fabricated. The sensor showed high resistive sensitivity and varied by more than four orders of magnitude with an increase in relative humidity (RH) from 11\% to 95\%. The response and recovery time were about $3.1 \mathrm{~s}$ and $76 \mathrm{~s}$, respectively with maximum hysteresis at $1 \% \mathrm{RH}$. In comparison with pure $\mathrm{SrTiO}_{3}$ and black $\mathrm{TiO}_{2}$, the gray composite based device exhibits a higher sensitivity. These results demonstrate the potential of gray $\mathrm{TiO}_{2} / \mathrm{SrTiO}_{3}$ for humidity sensing applications.
\end{abstract}

Keywords: humidity sensor; gray $\mathrm{TiO}_{2} / \mathrm{SrTiO}_{3}$ composite; semiconductor

\section{Introduction}

Humidity sensors play a crucial role in environment control, food science, plant cultivation, and the medical field [1]. In 1996-1998, high sensitivity humidity sensors using quartz oscillator and open capacitor were reported, which have advantages of fast response time, immunity to electromagnetic interference and high temperature stability. Besides, the differential sensors made of ceramic material are low-cost and required for high precision measurements [2,3]. Currently, the humidity sensing materials include semiconductors, perovskite oxides, and polymers [4-7]. Among these materials, sensors based on perovskite oxides are of high reliability and sensitivity. Some perovskite-type materials such as $\mathrm{NaTaO}_{3}, \mathrm{BaTiO}_{3}$ and $\mathrm{LaFeO}_{3}$ have been reported in the literature for their humidity detecting applications $[6,8,9]$.

$\mathrm{SrTiO}_{3}$ is recognized as one of the most promising perovskite oxides for sensing applications. Its wide band gap and large exciton binding energy induce excellent electrical and optoelectronic properties [10], owing to which the material conducts electrically at room temperature through the adsorption of water molecules on a surface. Interestingly, there has been limited research work performed on $\mathrm{SrTiO}_{3}$ based sensors and the primary focus has been on the conventional white $\mathrm{SrTiO}_{3}$ (band-gap $3.2 \mathrm{eV}$ for bulk material).

However, to the best of our knowledge, the sensing properties of dark colored $\mathrm{SrTiO}_{3} \mathrm{such}$ as humidity sensing, gas sensing, or photo-sensing characteristics have never been reported. Some research work regarding dark colored semiconductors was published by X. Chen in 2011. The black $\mathrm{TiO}_{2}$ with a narrow band-gap of $2.18 \mathrm{eV}$ shows great solar absorption for photocatalysis 
application [11]. Thereafter, the black $\mathrm{TiO}_{2}$ has attracted considerable attention due to their enhanced photoelectric properties [12]. In the current work, gray $\mathrm{TiO}_{2} / \mathrm{SrTiO}_{3}$ composite with a narrow band-gap was successfully prepared by a facile one-step synthetic method. The gray composite exhibits better humidity sensing performance in comparison with pure $\mathrm{SrTiO}_{3}$. Moreover, a narrow band-gap would be more favorable for generation of excited carriers and an increase in conductivity. Hence, sensors based on the dark colored semiconductors might possess more flexibility in realization of high performance multifunctional sensors, which endows composites with wider applications.

In the current work, gray $\mathrm{TiO}_{2} / \mathrm{SrTiO}_{3}$ composite nanocrystalline was synthesized in order to be used as a sensing material. Thereafter, the humidity sensor was fabricated by coating the material on carbon interdigitated electrodes. The humidity sensing characteristics were studied by measuring the impedance at different relative humidity (RH). The device shows excellent sensitivity, good linearity, and small hysteresis, which demonstrates that gray $\mathrm{TiO}_{2} / \mathrm{SrTiO}_{3}$ composite is a suitable candidate for humidity sensors.

\section{Experimental Procedure}

In the experiment, $14 \mathrm{~mL}$ tetrabutyl titanate was dissolved in $20 \mathrm{~mL}$ ethanol. Then, $1 \mathrm{~g}$ urea (used for $\mathrm{N}$ doping) was dropped to obtain solution $\mathrm{A}$, whereas solution $\mathrm{B}$ contained $5 \mathrm{~mL}$ deionized water, $10 \mathrm{~mL}$ ethanol, and $1 \mathrm{~mL}$ hydrochloric acid. Thereafter, solution $\mathrm{B}$ was gradually added dropwise to solution A under stirring with a glass rod until a white colloid was formed. Thereafter, colloid was kept in a water bath heated at $35^{\circ} \mathrm{C}$ for half an hour. Subsequently, equimolar $\mathrm{Sr}\left(\mathrm{NO}_{3}\right)_{3}(\mathrm{Sr}: \mathrm{Ti}=1: 1)$ was added into the mixture under magnetical stirring. The resulting material was calcined in $\mathrm{N}_{2}$ flow under atmospheric pressure at $500-800{ }^{\circ} \mathrm{C}$. The material synthesized at low temperature was $\mathrm{TiO}_{2} / \mathrm{SrTiO}_{3}$ composite; while that obtained at high temperature was more apt to form pure $\mathrm{SrTiO}_{3}$. The synthesized sample was mixed with deionized water in a weight ratio of 5:1 to form a paste. The paste was coated on a ceramic substrate $(1.0 \mathrm{~cm} \times 0.5 \mathrm{~cm})$ with four pairs of carbon interdigitated electrodes to form a sensitive film. The film was dried in vacuum at $60^{\circ} \mathrm{C}$. The preparation details of black $\mathrm{TiO}_{2}$ are given elsewhere [12].

The crystal structure of the sample was examined by X-ray diffraction (XRD, Bruker, D8 Advance, Karlsruhe, Germany). The optoelectronic characterization of the films was examined by PerkinElmer $\mathrm{UV} /$ Vis spectrometer (Lambda $650 \mathrm{~S}$, Waltham, MA, USA) at room temperature while Scanning electron microscope (SEM) (LEO1430VP, Zeiss, Jena, Germany) was used to investigate the morphology. The electrical properties of the sensor were measured by a Precision Impedance Analyzer 6500B Serious from Wayne Kerr Electronics (London, UK). For the humidity sensing properties test, the sensor was put into six chambers with different $\mathrm{RH}$ values. The $\mathrm{RH}$ values ranging from 11 to $95 \%$ were obtained via using different saturated salt solutions as humidity generation sources. These saturated salt solutions were $\mathrm{LiCl}, \mathrm{MgCl}_{2}, \mathrm{Mg}\left(\mathrm{NO}_{3}\right)_{2}, \mathrm{NaCl}, \mathrm{KCl}$, and $\mathrm{KNO}_{3}$ and the corresponding $\mathrm{RH}$ values were $11 \%, 33 \%, 54 \%, 75 \%, 85 \%$, and $95 \%$, respectively. The voltage was set at AC $1 \mathrm{~V}$ and the frequency changed from $40 \mathrm{~Hz}$ to $100 \mathrm{kHz}$ in humidity studies. All the above device performance tests were operated at room temperature controlled by air conditioning.

\section{Results and Discussion}

The X-ray diffraction (XRD) patterns of black $\mathrm{TiO}_{2}$, gray $\mathrm{TiO}_{2} / \mathrm{SrTiO}_{3}$ composite and pure $\mathrm{SrTiO}_{3}$ are shown in Figure 1a. The diffraction peaks of gray sample can be indexed to be peroviskite $\mathrm{SrTiO}_{3}$ and brookite $\mathrm{TiO}_{2}$ composite. The black sample corresponds to the black $\mathrm{TiO}_{2}$ with anatase type, and the third sample shows pure $\mathrm{SrTiO}_{3}$ with perovskite structure.

The dark color indicates the enhanced light absorption of the sample. The UV-visible absorption spectrum of gray $\mathrm{TiO}_{2} / \mathrm{SrTiO}_{3}$ composite is shown in Figure $1 \mathrm{~b}$. It is found that the absorption edge of the composite is approximately defined, which shows that absorption of the gray sample in visible light region is enhanced, in comparison with pure $\mathrm{SrTiO}_{3}$. According to the relationship between band-gap and absorption edge, $\mathrm{Eg}=1240 / \lambda$ (where $\mathrm{Eg}$ is the band-gap of semiconductor, $\lambda$ is the 
light wavelength), the band gap of composite is estimated to be less than $2 \mathrm{eV}$ [13]. These results demonstrate the potential of the composite in photo-sensitive applications. Inset is the picture of actual humidity sensors based on the three samples, respectively.

Figure $2 \mathrm{a}$, $\mathrm{b}$ display the general morphology of the gray $\mathrm{TiO}_{2} / \mathrm{SrTiO}_{3}$ composite studied via SEM at different resolutions. It shows that the composite has a cube shape and the average size is about $150 \mathrm{~nm}$. A uniform and crack-free $\mathrm{TiO}_{2} / \mathrm{SrTiO}_{3}$ sample is obtained, demonstrating that the composite is suitable to act as a substrate material for humidity sensors.
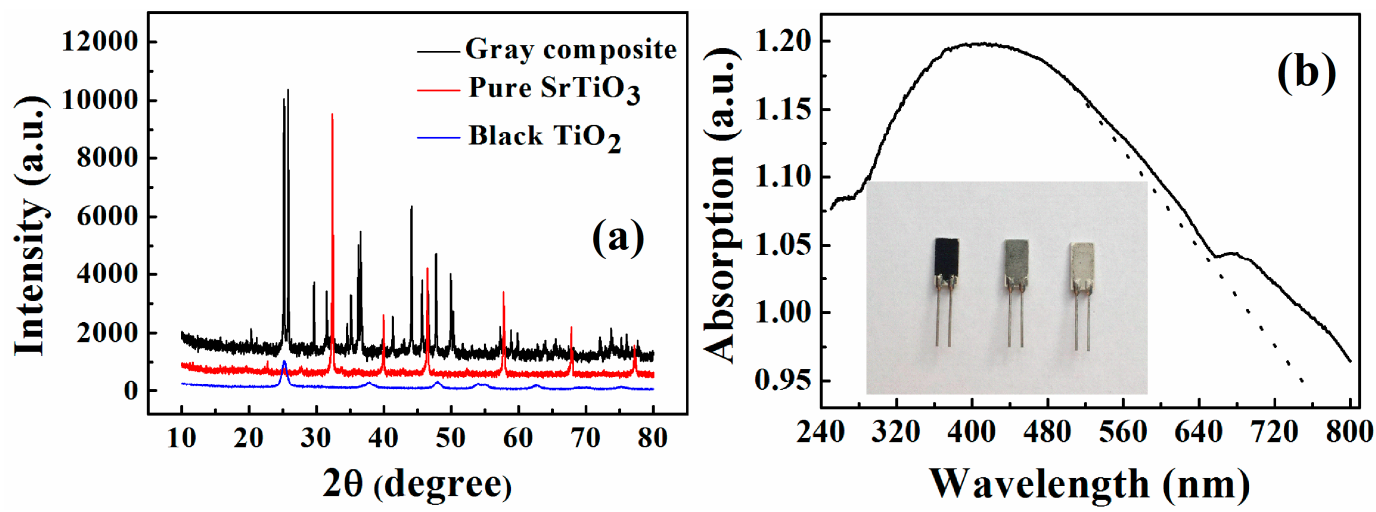

Figure 1. (a) X-ray diffraction (XRD) patterns of $\mathrm{TiO}_{2}, \mathrm{TiO}_{2} / \mathrm{SrTiO}_{3}$, and $\mathrm{SrTiO}_{3}$; (b) UV-Visible absorption spectrum of gray $\mathrm{TiO}_{2} / \mathrm{SrTiO}_{3}$ composite; Inset is the picture of humidity sensors based on different samples.

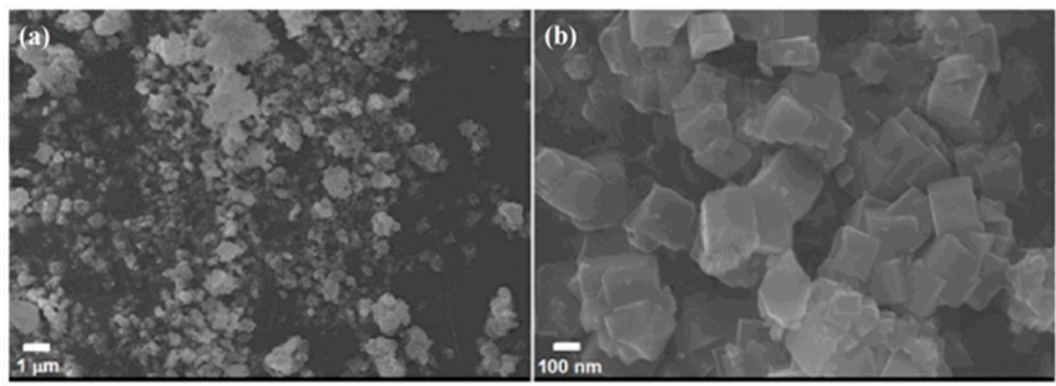

Figure 2. The SEM images of $\mathrm{TiO}_{2} / \mathrm{SrTiO}_{3}$ composite at low (a) and high (b) resolutions.

The relationship between impedance and $\mathrm{RH}$ for $\mathrm{TiO}_{2} / \mathrm{SrTiO}_{3}$ humidity sensor at various frequencies is shown in Figure 3a. In the low frequency regions $(50 \mathrm{~Hz}$ and $100 \mathrm{~Hz}$ ), it can be seen that the impedance decreases with an increase in frequency and changes by far more than four orders of magnitude with a gradual increase in $\mathrm{RH}$. The sensor presents a higher sensitivity compared with other $\mathrm{ABO}_{3}$-structured semiconductors reported previously, such as $\mathrm{SrTiO}_{3}$ nanospheres, $\mathrm{NaTaO}_{3}$, $\mathrm{BaTiO}_{3}[6,8,14]$. The high sensitivity is closely related to the $\mathrm{N}$-doping in composite, which induces more oxygen vacancies as an active site to adsorb more water molecules [12].

Additionally, at low frequencies, RH has a close-to-linear relationship with impedance, while there is no clear linearity of relationship at high frequencies. A high sensitivity and good linearity can be obtained at $100 \mathrm{~Hz}$. Hence, $100 \mathrm{~Hz}$ was chosen as the ideal working frequency. Moreover, the impedance of referent ceramic substrate remained constant w.r.t change in $\mathrm{RH}$, which signifies that the substrate has no contribution in humidity sensing.

Figure $3 \mathrm{~b}$ shows the impedance versus $\mathrm{RH}$ curves of sensors based on different samples at $100 \mathrm{~Hz}$. The sensitivity of pure $\mathrm{SrTiO}_{3}$ device changes by about three orders of magnitude while that of black $\mathrm{TiO}_{2}$ changes within one order of magnitude. The gray sample-based sensor exhibited a much higher sensitivity in comparison with that of black $\mathrm{TiO}_{2}$ and pure $\mathrm{SrTiO}_{3}$. The composites 
composed of different materials usually combine advantages of the components with better properties. For example, $\mathrm{In}_{2} \mathrm{O}_{3}-\mathrm{NiO}, \mathrm{ZnO}-\mathrm{In}_{2} \mathrm{O}_{3}$ and $\mathrm{MoO}_{3}-\mathrm{NiO}$ composites all exhibited enhanced humidity sensitive characteristics $[5,15,16]$. The strengthened moisture properties may be attributed to the improved specific surface area and more active sites in composite. A large surface area-to-volume ratio means that a significant fraction of the atoms or molecules are surface atoms that can participate in surface reactions $[15,16]$.
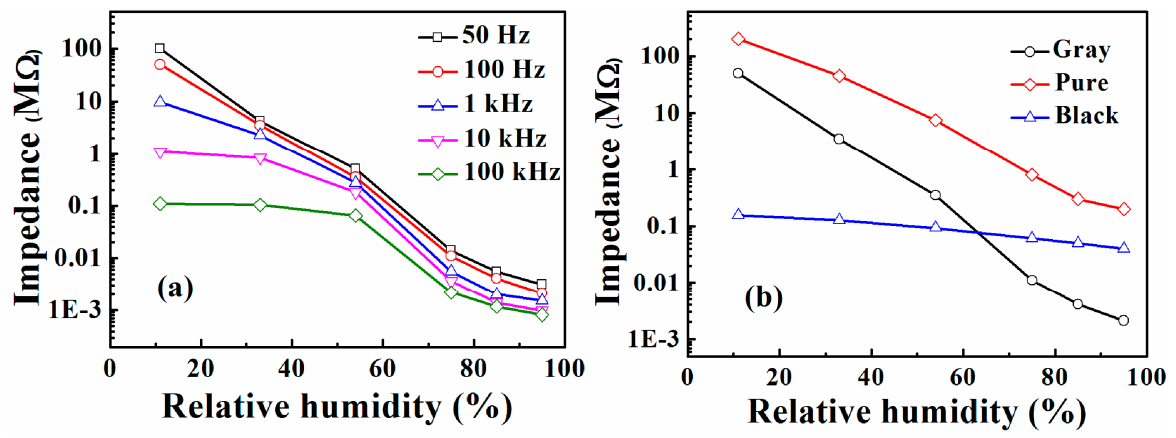

Figure 3. (a) Impedance versus relative humidity (RH) curves of $\mathrm{TiO}_{2} / \mathrm{SrTiO}_{3}$ humidity sensor at various frequencies; (b) The Impedance versus RH curves of sensors based on different samples.

Figure 4 shows the humidity hysteresis characteristic of the composites between the adsorption and desorption process at $100 \mathrm{~Hz}$. The $\mathrm{TiO}_{2} / \mathrm{SrTiO}_{3}$ sensor appeared to have a narrow hysteresis loop. The maximum hysteresis of the device was about $1 \% \mathrm{RH}$, which was smaller than that of the pure $\mathrm{SrTiO}_{3}$ (less than $2 \% \mathrm{RH}$ as measured).

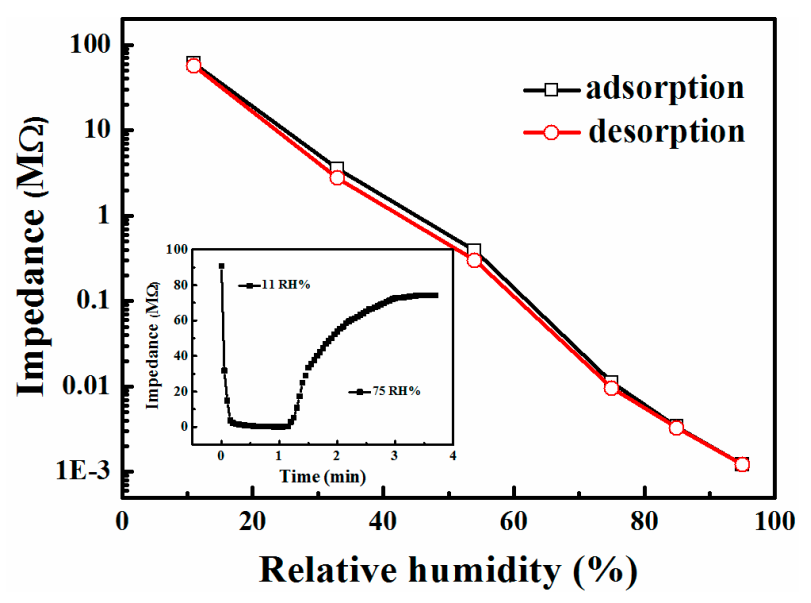

Figure 4. Humidity hysteresis characteristics of $\mathrm{TiO}_{2} / \mathrm{SrTiO}_{3}$ sensor measured at $100 \mathrm{~Hz}$ and AC $1 \mathrm{~V}$; Inset shows the response and recovery behavior of $\mathrm{TiO}_{2} / \mathrm{SrTiO}_{3}$ humidity sensor.

The response time is the time taken by a sensor to achieve $90 \%$ of the total resistance change in the case of adsorption process or the recovery time in the case of desorption process. Since the humidity detection range primarily covers the range of $11 \% \mathrm{RH}-75 \% \mathrm{RH}$, the response and recovery characteristics of the sensor in this range were measured at $100 \mathrm{~Hz}$, as shown in the inset. The response time for the change from $11 \% \mathrm{RH}$ to $75 \% \mathrm{RH}$ was about $3.1 \mathrm{~s}$, and recovery time for the change from $75 \%$ RH to $11 \%$ RH was about $76 \mathrm{~s}$.

To have an enhanced understanding of the sensing mechanism, the complex impedance plots of $\mathrm{TiO}_{2} / \mathrm{SrTiO}_{3}$ sensor at different $\mathrm{RH}$ are presented in Figure 5 for the frequency range of $40 \mathrm{KHz}$ to $100 \mathrm{kHz}$. At low RH, only a few water molecules are adsorbed by chemisorption on the active site of the composite surface to form hydroxyl groups. Subsequently, protons would be transferred 
from the surface hydroxyl groups to water molecules to form hydronium ions $\left(\mathrm{H}_{3} \mathrm{O}^{+}\right)$[6]. Though the density of $\mathrm{H}_{3} \mathrm{O}^{+}$is low and the transfer of carriers is difficult, the charge carriers would bring about electrons accumulation and bend the energy-band at the grain surface, leading to a decreased resistance. Meanwhile, bounded electrons emerge by means of polarization of the sensing material. At this time, the dominant conducting carriers are $\mathrm{H}_{3} \mathrm{O}^{+}$and bounded electrons [17].

Starting from the spectrum of $54 \% \mathrm{RH}$, an evident straight line in the low frequency region appears which is the consequence of diffusion and polarization of charged carriers between sensing film and electrodes [18]. With the RH increase, many more water molecules are adsorbed on the surface and tend to form a liquid-like layer, in which a proton transfers between neighboring water molecules. Hence, protons become dominant charged carriers at high RH. Correspondingly, the semicircle in the high frequency region fades away and the straight line in the low frequency region becomes very obvious.
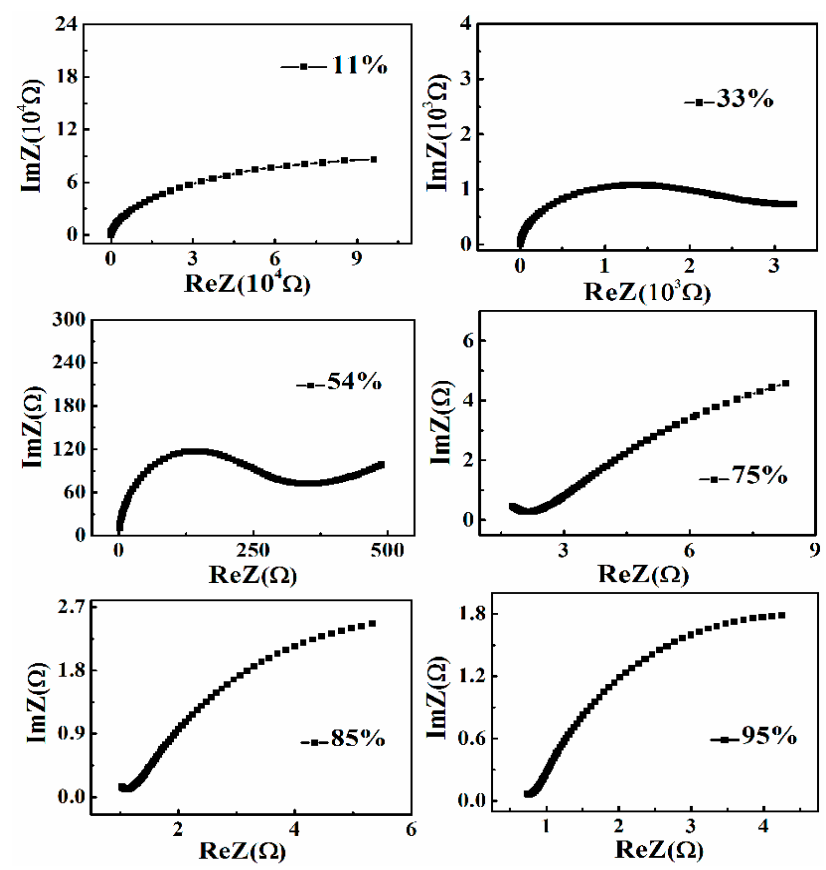

Figure 5. Complex impedance properties of the composite measured at different $\mathrm{RH}$.

It is well known that the characteristic frequency corresponds to the value when the imaginary part of the complex impedance spectrum reaches its maximum, near which is known as the dispersion region. Seen from the spectra in Figure 5, the dispersion region gradually moves toward high frequency as the RH increases, which reveals that the space-charge polarization does exist in the sensor. Based on the research proposed by Paula Vilarinho et al., the dielectric constant of $\mathrm{SrTiO}_{3}$ increases as the frequency increases, then the polarization of adsorbed water molecules is enhanced with increasing $\mathrm{RH}[19]$.

\section{Conclusions}

In conclusion, the synthesis, characterization, and humidity sensing of $\mathrm{TiO}_{2} / \mathrm{SrTiO}_{3}$ were investigated. The impedance changes by more than four orders of magnitude in the range from $11 \%$ to $95 \% \mathrm{RH}$ at $100 \mathrm{~Hz}$, and the maximum hysteresis is about $1 \% \mathrm{RH}$. Furthermore, the sensing mechanism was discussed by the complex impedance spectra in detail. These results demonstrate the potential application of the composite in fabricating high performance humidity sensors.

Acknowledgments: The authors are grateful to the National Natural Science Foundation of China (Grant No. 51602273), the Natural Science Foundation of Xinjiang University (BS160218), Thousand Youth Talents Plan 
(Y42H831301), the Foundation of Director of Xinjiang Technical Institute Physics \& Chemistry CAS (2015RC010), Technological Innovation Youth Training Project of Xinjiang Uyghur Autonomous Region (QN2015YX004) for the support to the work.

Author Contributions: W.R. and R.W. conceived and designed the experiments; M.Z. and S.W. performed the experiments; M.Z. analyzed the data; M.Z. contributed reagents/materials/analysis tools; M.Z. wrote the paper.

Conflicts of Interest: The authors declare no conflict of interest.

\section{References}

1. Chimica, D.; Materiali, I.; L'Aquila, U. Microstructure and humidity-sensitive characteristics of a-Fe $\mathrm{O}_{3}$ ceramic sensor. J. Am. Ceram. Soc. 1992, 75, 546-551.

2. Matko, V.; Koprivnikar, J. Quartz sensor for water absorption measurement in glass-fiber resins. IEEE Trans. Instrum. Meas. 1998, 47, 1159-1162. [CrossRef]

3. Matko, V.; Donlagic, D. Sensor for high-air-humidity measurement. IEEE Trans. Instrum. Meas. 1996, 45, 561-563. [CrossRef]

4. Phan, D.; Chuang, G. Effects of rapid thermal annealing on humidity sensor based on graphene oxide thin films. Sens. Actuators B Chem. 2015, 220, 1050-1055. [CrossRef]

5. Liang, Q.; Xu, H.; Zhao, J.; Gao, S. Micro humidity sensors based on ZnO- $\operatorname{In}_{2} \mathrm{O}_{3}$ thin films with high performances. Sens. Actuators B Chem. 2012, 165, 76-81. [CrossRef]

6. Zhang, Y.; Yu, Y.; Zhang, Y.; Cheng, X.; Feng, C.; Chen, L.; Zhou, J.; Ruan, S. A novel humidity sensor based on $\mathrm{NaTaO}_{3}$ nanocrystalline. Sens. Actuators B Chem. 2012, 174, 485-489. [CrossRef]

7. Fei, T.; Jiang, K.; Liu, S.; Zhang, T. Humidity sensor based on a cross-linked porous polymer with unexpectedly good properties. RSC Adv. 2014, 4, 21429-21434. [CrossRef]

8. Xia, Y.; Fei, T.; He, Y.; Wang, R.; Jiang, F.; Zhang, T. Preparation and humidity sensing properties of $\mathrm{Ba}_{0.8} \mathrm{Sr}_{0.2} \mathrm{TiO}_{3}$ nanofibers via electrospinning. Mater. Lett. 2012, 66, 19-21. [CrossRef]

9. Zhao, J.; Liu, Y.; Li, X.; Lu, G.; You, L.; Liang, X.; Liu, F. Highly sensitive humidity sensor based on high surface area mesoporous $\mathrm{LaFeO}_{3}$ prepared by a nanocasting route. Sens. Actuators B Chem. 2013, 181, 802-809. [CrossRef]

10. Rossella, F.; Galinetto, P.; Samoggia, G.; Trepakov, V.; Jastrabik, L. Photoconductivity and the structural phase transition in $\mathrm{SrTiO}_{3}$. Solid State Commun. 2007, 141, 95-98. [CrossRef]

11. Chen, X.; Liu, L.; Yu, Y.; Mao, S. Increasing solar absorption for photocatalysis with black hydrogenated titanium dioxide nanocrystals. Science 2011, 331, 746-750. [CrossRef] [PubMed]

12. Wei, S.; Wu, R.; Jian, J.; Chen, F.; Sun, Y. Black and yellow anatase titania formed by (H,N)-doping: Strong visible-light absorption and enhanced visible-light photocatalysis. Dalton Trans. 2015, 44, 1534-1538. [CrossRef] [PubMed]

13. Zhang, M.; Liu, G.; Zhang, D.; Chen, Y.; Ruan, S. Facile fabrication of $\mathrm{NaTaO}_{3}$ film and its photoelectric properties. J. Alloys Compd. 2014, 602, 322-325. [CrossRef]

14. Li, D.; Zhang, J.; Shen, L.; Dong, W.; Feng, C.; Liu, C.; Ruan, S. Humidity sensing properties of $\mathrm{SrTiO}_{3}$ nanospheres with high sensitivity and rapid response. RSC Adv. 2015, 5, 22879-22883. [CrossRef]

15. Feng, C.; Li, W.; Li, C.; Zhu, L.; Zhang, H.; Zhang, Y.; Ruan, S.; Chen, W.; Yu, L. Highly efficient rapid ethanol sensing based on $\mathrm{In}_{2-\mathrm{x}} \mathrm{Ni}_{\mathrm{x}} \mathrm{O}_{3}$ nanofibers. Sens. Actuators B Chem. 2012, 166-167, 83-88. [CrossRef]

16. Li, D.; Li, Y.; Li, F.; Zhang, J.; Zhu, X.; Wen, S.; Ruan, S. Humidity sensing properties of $\mathrm{MoO}_{3}-\mathrm{NiO}$ nanocomposite materials. Ceram. Int. 2015, 41, 4348-4353. [CrossRef]

17. Wang, J.; Su, M.; Qi, J.; Chang, L. Sensitivity and complex impedance of nanometer zirconia thick film humidity sensors. Sens. Actuators B Chem. 2009, 139, 418-424. [CrossRef]

18. Xie, W.; Liu, B.; Xiao, S.; Li, H.; Wang, Y.; Cai, D.; Wang, D.; Wang, L.; Liu, Y.; Li, Q.; et al. High performance humidity sensors based on $\mathrm{CeO}_{2}$ nanoparticles. Sens. Actuators B Chem. 2015, 215, 125-132. [CrossRef]

19. Pashkin, A.; Samoukhina, P.; Ostapchuk, T.; Kužel, P.; Vilarinho, P.; Petzelt, J. Submillimeter and far infrared dielectric response of Bi-doped $\mathrm{SrTiO}_{3}$ ceramics. Ferroelectrics 2003, 294, 133-139. 